\title{
Construction of Case Teaching Model for Management Specialty Supported by Information Technology
}

\author{
Wei LI, Ruijin ZHOU, Peiqi DENG, Qiang FANG, Pengwei ZHANG \\ Henan Institute of Science and Technology Xinxiang, Henan Province, China, 453003
}

\begin{abstract}
Case teaching model for management specialty is helpful to improve the students' ability of comprehensive solving problems and cultivate the students' consciousness of unity and cooperation. Information technology in the case teaching model plays an important role in enhancing students' perceptual knowledge, kindling the students' active thinking, cultivating students' comprehension and expression ability and improve their capacity for independent learning, which is helpful to realize the talent training goal for management specialty.
\end{abstract}

Index Terms: information technology, case teaching model, management specialty

(C) 2012 Published by MECS Publisher. Selection and/or peer review under responsibility of the International Conference on E-Business System and Education Technology

\section{Introduction}

At present, most institutions set up comprehensive management major, such as business management, business administration, marketing, business management and so on. In order to cultivate practical ability of students, the teaching methods such as simulation and simulation operation are used, in addition the case teaching model is also a widely used effective teaching methods. In case teaching model, through the description of a specific situation, guide students to apply theoretical knowledge and skills to analyze these cases, discussion treatment options to improve the creativity of students, the use of the existing theoretical knowledge to analyze and solve practical problems in a teaching mode. In the case teaching model, teachers need to guide the students how to combine theory with practice, combine knowledge and experience, combine curricular and extracurricular and combine school and out school organically, how to solve problems in a creative way, and through this teaching model, it can improve the students' comprehensive ability to solve problems, cultivate students' team cooperation consciousness and promote the students' overall harmonious development. In the process of teaching professional courses in management, the implementation of case teaching model can help students to learn, digest, understand and apply the knowledge, capacity and quality for the ability to achieve increased by the changes in knowledge, training and management talent to achieve goals. 


\section{Advantage of Information technology in the case teaching}

By using information technology the word, figure, voice and image can be made together, and these contents are intuitive, visualize and vivid, which can improve the students' sensibility cognition, understand ability and space imagination, illumine association of ideas, lead to positive thinking. At the same time, by this way we can learn from other schools. A network of teaching resources and the latest research dynamic and research results and introduce them to students. Information technology has become the most important means of improving education quality and teaching conditions.

\subsection{Big Information And High Speed.}

The figure, word, voice, picture and image and other ways of information are unfolded to students, which can make the abstract into substance, complex and difficult to easy. Sometimes it is different to explain the question in language, by multimedia will soon be revealed in fact, it allows students to look and feel and understand more and more conducive to training and development of students the thinking, observation, and imagination and innovation ability.

\subsection{Visual In Image.}

Information technology can create a sound synchronized context, dynamic static integrated teaching image, lively teaching environment, which can break the ocular limit; many traditional teaching methods are very difficult to convey the teaching content or cannot display the phenomenon visually, lively and directly into students. Information technology give students more point to see objects and to highlight the main point, which help to understand the concept, command the method and improve the learning interest.

\subsection{The Reproducibility.}

Because of the using of media and network technology and information technology, information can be replayed at all or part, and which is beneficial to avoid disremembering, and enhance understanding and memory.

\subsection{Improving Teaching Efficiency.}

Modern pedagogy practice shows that people's knowledge from hearing can maintain $70 \%$ after three hours, and after three days it has only $10 \%$; the knowledge from seeing can maintain $85 \%$ after three hours, and after three days it has $20 \%$; if the knowledge from hearing and seeing can maintain $85 \%$ after three hours, and after three days it has $65 \%$. So the multimedia teaching method can increase the teaching efficiency markedly.

\subsection{Saving Time.}

A lot of information is put up by multimedia, so a lot of space and time are saved, that is beneficial to solving the contradiction between many teaching contents and little teaching time.

\section{Characteristic of case teaching model for management specialty supported by information technology}

The concept of case teaching model for management specialty supported by information technology is a model which is based on the modern education thought, teaching theory and learning theory, to make full use of the auspice of modern information technology and limitless information resource, to make up a good learning environment, to give full play to the students' initiative, enthusiasm and creationary.

\section{1 Making Full Use of Modern Information Technology Is The Basic Characteristics.}

Modern information technology which is an indispensable part of case teaching model is not only the teaching assistant tool and learning tool, but also provides limitless information resource for learning. So the modern information is one of the learning environment that likes classroom and blackboard. 


\section{2 Keeping To The Ability Principle And Practice Principle, Playing The Students' Initiative, Enthusiasm And Reactionary, Culturing Students' Comprehensive Ability.}

After analysis discussing a lot of cases, students not only obtain various experiences, but also can sum up many principles, methods, experiences and lessons. These can reflect a inherent law of something in the specific era. When the students learn the law, they can adapt to complicated work environment, and enhance their emergency ability and adaptability.

\section{3 Advocating The Participation Principle.}

The teaching model should be multiplicity, and in the teaching process there are many interaction between the teacher and student, the student and student, the teacher and teacher. In the case teaching the information technology is used reasonably, and the students' initiative, enthusiasm and creationary are increased, the interations between the teacher and student, the student and student, the teacher and teacher are added. Only by this way the case teaching model is successful.

\section{4 Avoiding The Misunderstanding In Using Information Technology In Case Teaching, Improving The Teacher's Teaching Level And Teaching Effect.}

Any teaching method has advantages and disadvantages, and the key is how to use them. The teacher should chose an appropriate case that makes real problem as the research object, bases on fact and makes theory knowledge into the case. In the process of analysising the case, students can make perceptual knowledge rise to rational knowledge, which can instruct the their practice activity. The other hand, the multimedia technology should be used reasonable in case teaching model.

\section{Construction of Case Teaching Model for Management Specialty Supported by Information Technology}

The construction of case teaching model is based on the case learning task, and the soul of teaching model is planning and providing the learning task. The different learning task has different teaching model, and the same learning task may have different teaching model. Taking the analysis of students' character and teaching aim as the basis, the learning task is planned and provided. The construction of case teaching model can be began from situation creation and teaching strategy creation. Situation creation can make the learning task into real promble, which is benefict to improving the students' knowledge and ability. Teaching strategy creation can show clearly direction for students and provide many models to solve problems.

The key of this teaching model is using the medern information technology to build a learning environment where the students can play their initiative, enthusiasm and creationary. The learning environment has some characteristics such as information resources rich, convenient in communication and open time and space. In this environment the students not only can study freely which can culture their associative thinking, creative thinking and creative ability, but also can increase the interaction between the student and student, between teacher and student, and form a cooperative spirit and good interpersonal relationship.

\section{1 Improving The Students' Independent Learning Ability.}

In the teaching process, the student need independently use the theory from books, find the case, analyze the case, write the paper, lecture and evaluate the result. The students exercise their self-study spirits through these independent behaviors. Some students say that this new teaching model provides new opportunities for them to show their genius and pioneer innovation.

\section{2 Development of Positive Thinking And Creative Thinking.}

It is important of the traditional teacher-centered instruction with the sole purpose of teaching knowledge and skills in higher education, which emphasize the integrity, systemic and coherence of knowledge. But the overstress on the integrity, systemic and coherence in higher education makes the students have no time to study the 
modern most forward knowledge before graduation, and that is the disadvantages of traditional teacher-centered instruction. By means of connection with practice, self-study, discussion and lecture and so on, the case teaching model provides a big study arena for students, promotes the development of students' positive thinking and creative thinking, and obtains the enthusiastic support of students.

\section{3 Improving The Language Expression}

In the case teaching, the student should lecture, ask, argue and answer the temporary questions, and which is beneficial for students to improve their language expression and emergency reaction ability. Comparison of different student's lecture, they will have their opinion and they can summarize experience and lesson, which is good for them to interview in future. If the teacher explains this point to students before the case teaching, the students' lecture positivity will be aroused. Many students' self-confidence will be increased after a successful lecture.

\section{4 Initiating A Lively Studying Situation}

If there is no dialog, there is no communion. If there is no communion, there is no education. The teaching was teacher dominant in the past, but now the teaching is democratic. The students are allowed not only to ask quentions in class, but also to discourse and advise on questions in some degree. Both classroom teaching and learning atmosphere are good. In class the students speak actively. In addition, the students prepare learning content positively before class, which initiates a lively new studying situation.

\section{Information technology in case teaching should avoid some mistakes}

\section{1 Form Is Important Then Content and Luxuriance But Not Practical.}

When some teachers using information technology in class, they usually stay on lip service. They often think that only plenty of animation and sound can attract students' attention. Colorful interface, pretty button, change multiplicity text are designed to beautifying interface and easy to teachers operation. But all these will disperse students' attention for teaching content.

\section{2 Lack of Interests.}

The objective of using information technology to assisted instruction is using image, sound, animation and other means to stimulate the sensory of students and attract interests of students. At last, teaching efficiency and teaching effect will be improved. A multimedia courseware with single forms is only a move of textbook and has no difference with teaching method of blackboard adds chalk. The teaching effect is not significant naturally and will do any well for assisted instruction.

\section{3 Abusing Information Technology, Thinking Ability And Imaginative Ability All Are Weakened.}

Information technology is used in case teaching can change abstract problem into image of problems, and this can help students to master and understand the abstract content. But, using too much information technology certainly will affect the logical thinking ability of students to be provided. It may lighten the students to study the difficult points of concern, and affect the teaching of the actual effect.

\section{4 Teachers Become An Appendage of Information Technology And This Can not Give Any Profit For Improving Education Levels.}

Excessive using multimedia and other information technology in teaching has seriously restricted the teacher's professional development especially young college teachers. Electronic library, teaching resource bank, various electronic publication and the abundant information resources what in internet have provide abundant teaching resources for teachers. It has greatly provided convenient for teachers study and research. But it also has leaded to bad thing which is that teachers can not summarization, digestion and absorption. Teachers become genuinely 
“operation”. If this be developed longer, it necessarily restricts the teachers' professional development and effect to provide teaching quality.

\section{Several problems should be pay attention to in case teaching}

\section{1 Choiceness Cases And Detail Explanation Cases Used Together}

The objective of case teaching is in order to enhance teaching effect. So the selected cases must agree with teaching content and have some popularity, conciseness, typicality. This is easy for students to accurately basic viewpoint and basic principle of textbook. Give students a wide thinking space. Let students found problems and thinking problems from different angles and provide angles suggestions for them.

\section{2 The Method of Solving Problems Must Be Rich.}

The important thing case teaching is quality education and to culture creative ability. So, teachers should encourage divergent thinking of students. And encourage students thinking problems from different angles or different way to solve problems. Encourage students using different strategies to reach expected target. With the different strategies what be proposed by students, teachers should guide students to found the unique value of each methods. When teachers cognitive problems, analysis problems and solve problems, they should to do these with different people, different things, different time and different location. Teachers can not use standard answer to durance the creative consciousness of students. In order to make students all understand what's wrong with them, those obviously errors or unilateral understanding and view must be clearly stated by teachers. They can avoid the similar errors occurred again in future.

\section{3 Teachers Must Make A Good Knowledge of The Reserves.}

Teachers must have sufficient grasp with cases, and have enough preparing with the design of teaching plan, and have sufficient foreseeability with possible problems. Only all the above problems have been noticed, teachers can do good application effect with the reserves and guide students to take part in the discussion. And cope with the problems or opinions which be proposed by students from different angles. Otherwise, it is likely to appearance awkward position because he teacher can't give a satisfactory answer.

\section{References}

[1] Wang Min, “Case analysis in the application of MPA education”, Jiangxi Administration Institute, vol. 1, pp: 15-18, 2001.

[2] Liu Gang, "Know the real Harvard Business School case study”, Digital Business Times, vol, 9, pp:2-3 , 2005.

[3] Zhang Fang, "To carry out the role of simulation experience activities should follow the principle", Contemporary Education Forum, vol. 4, pp: 20, 2004. 